\title{
Integrating stakeholder perspectives into the translation of cell-free fetal DNA testing for aneuploidy
}

Lauren C Sayres ${ }^{* *}$, Megan Allyse ${ }^{1}$ and Mildred K Cho ${ }^{1,2}$

\begin{abstract}
Background: The translation of novel genomic technologies from bench to bedside enjoins the comprehensive consideration of the perspectives of all stakeholders who stand to influence, or be influenced by, the translational course. Non-invasive prenatal aneuploidy testing that utilizes cell-free fetal DNA (cffDNA) circulating in maternal blood is one example of an innovative technology that promises significant benefits for its intended end users; however, it is currently uncertain whether it will achieve widespread clinical implementation. We conducted qualitative interviews with 18 diverse stakeholders in this domain, including prospective users of the technology and healthcare personnel, researchers and developers, and experts in social, legal, and regulatory aspects of genetic technology, and a pilot survey of 62 obstetric healthcare providers. Analysis of interview and survey data was combined with a review of the proceedings of a full-day, multidisciplinary conference on the topic and published scientific and ethics literature surrounding this and other relevant technologies.

Discussion: We constructed potential pathways for technological implementation, identified broad stakeholder classes party to these translational processes, and performed a preliminary assessment of the viewpoints and interrelations among these diverse stakeholders. Some of the stakeholders whose priorities are critical to understand and integrate into translation include pregnant women and their families; healthcare providers; scientists, their institutions or companies, and the funding agencies that support them; regulatory and judicial bodies; third-party payers; professional societies; educational systems; disability rights communities; and other representatives from civil society. Stakeholder interviews, survey findings, and conference proceedings add complexity to these envisioned pathways and also demonstrate a paramount need to incorporate an iterative stakeholder analysis early and throughout the translational endeavor. We believe that the translational framework that we have developed will help guide crucial future stakeholder mapping and engagement activities for cffDNA aneuploidy testing and inform novel methods of technology assessment for other developments in the growing field of genomic medicine.
\end{abstract}

Summary: Mapping potential pathways for implementation and exploring the attitudes and interrelations of diverse stakeholders may lead to more effective translation of a novel method of prenatal aneuploidy testing.

\section{Background}

The 2011 vision of the National Human Genome Research Institute aspires to fulfill the ultimate goal of the Human Genome Project by applying the results of genomic research to diverse areas of healthcare [1]. However, this vision appears to be based on the assumption

\footnotetext{
* Correspondence: Icsayres@stanford.edu

'Stanford Center for Biomedical Ethics, Stanford University, 1215 Welch Road Modular A, Stanford, California, 94301, USA

Full list of author information is available at the end of the article
}

that translation is primarily a matter of greater understanding of biology and development of genomic technology. Instead, we suggest that successful genomic translation also requires the design of translational pathways that take into account the objectives and values of a wide range of stakeholders. Because translation of medical technologies rarely proceeds down a path of inevitable advances, we propose that translation is more likely when all stakeholder perspectives are deeply integrated into each phase of the research, development, implementation, and policy-making
C Biomed Central

(C) 2012 Sayres et al.; licensee BioMed Central Ltd. This is an open access article distributed under the terms of the Creative Commons Attribution License (http://creativecommons.org/licenses/by/2.0), which permits unrestricted use, distribution, and reproduction in any medium, provided the original work is properly cited. 
process [2-8]. To be successful, these pathways must additionally be mindful of broader context: the existence of related technologies, social dynamics and stakeholder convictions about these technologies, and existing political and economic frameworks for translation and use. As evidenced by the thwarted translation of other promising genetic technologies, such as genetically modified crops and gene transfer technologies, a failure to explore contextual elements in advance of translation may result in unfulfilled stakeholder expectations, stakeholder frustration and resistance, and ultimately, translational failure, even after a new biotechnology has been made commercially available [9-11].

By exploring potential translational pathways in the context of one nascent application of genetic technology prenatal aneuploidy testing using cell-free fetal DNA (cffDNA) - we illustrate how stakeholder perspectives may have significant and direct effects on the course of translation. We hope that the development of this framework of translational pathways and stakeholder interactions provides impetus for a more textured evaluation of the influences and interests of diverse stakeholders and continuous engagement of these actors in implementing cffDNA technology. Furthermore, we believe that this broad methodology for technology assessment - moving beyond evaluation of the primary characteristics of a technology towards a comprehensive integration of stakeholder values and contextual elements - may be applied to other genomic technologies with unique sets of stakeholders and divergent translational pathways.

\section{Tracing translational pathways for cffDNA testing for aneuploidy}

Several recent studies have demonstrated that cffDNA in maternal blood can be used for the non-invasive prenatal detection of aneuploidy [12-16]. Because this testing requires only a maternal blood draw - eliminating any risk of miscarriage - and can be performed earlier in pregnancy than existing tests, cffDNA testing has the potential to make aneuploidy testing routine for all pregnancies. Several companies have announced plans to commercialize cffDNA testing for aneuploidy, including trisomy 13, 18, and 21 (Down syndrome), and three companies have already started to offer trisomy testing in the United States [17-20]. Although substantial media attention has been directed towards the introduction of these tests, it is not clear whether the development of this technology will lead to the immediate and widespread adoption that some observers predict [21].

This analysis has been conducted to explore the underlying values of diverse actors in the research, development, and use of cffDNA technology in order to guide the translational enterprise [22-24]. As the first stage in this assessment, we interviewed 18 stakeholders with diverse interests in this realm to sketch the landscape of the technology and its ethical, legal, and social context and to understand how various stakeholders conceptualize translation. Stakeholders were identified as representatives of previously described parties to genetic technology translation, including prospective technology adopters, various healthcare personnel, academic researchers, commercial developers, community activists, and experts on law and regulation in this arena, through citation in the academic literature and media and via snowball sampling $[4,24,25]$. Semi-structured interviews were conducted, lasting approximately one hour each. We also conducted a pilot survey of 62 healthcare providers in attendance at a Continuing Medical Education conference on advances in obstetrics and gynecology; the findings from this survey have been published elsewhere but are provided as important references for this analysis [26]. Our Institutional Review Board approved both the series of interviews and survey, and all interview and survey subjects provided consent to participate. We also reviewed the transcripts of a full-day, multi-disciplinary conference, 'The Coming Revolution in Prenatal Genetic Testing? Scientific, Ethical, Social, and Policy Responses to Maternal Serum Cell-free Fetal DNA Testing', jointly hosted by the Stanford University School of Medicine and Stanford Law School in May 2010, and pertinent academic literature on cffDNA testing, related technologies, and surrounding ethical, legal, and social implications [16].

\section{Discussion \\ Results}

Throughout data collection and review, we began to narrow in on six classes of relevant stakeholders while tracing how the technology might be translated from bench to bedside. Iterative feedback from colleagues knowledgeable about the technology confirmed that our framework was a legitimate and useful tool for identifying stakeholders and assessing their influences and interrelations in the translational context. The findings of our interviews, survey, and the multi-disciplinary conference add nuance to many of the translational complexities and contingencies set forth by the National Human Genome Research Institute's vision and inform the specific translational pathways that we describe. These data suggest that a wide range of scientific and social factors, including characteristics of the existing system of prenatal care and testing but beyond simply the technical characteristics of cffDNA testing, may affect implementation.

In the following sections, organized by our six identified stakeholder classes, we sketch potential translational pathways for cffDNA testing for aneuploidy, including their points of divergence, and the individuals and institutions that influence, and may be influenced by, their progress. Increasingly complex diagrams of these 
pathways (Figures 1 to 6) are presented as additional sets of stakeholder interactions are explored. These pathways are not mutually exclusive but are delineated in order to highlight their salient features and ethical, legal, and social consequences for stakeholders. Where appropriate, concrete policy recommendations are presented.

\section{Resource allocation}

Funding for the research, development, and initial application of a technology is necessary to any translational endeavor (Figure 1). The allocation of resources for the translation of cffDNA testing demands sufficient expectation that the current uncertainties regarding the promised value of this technology will resolve favorably [27]. Additionally, mobilization of all resources - capital, equipment, and personnel - will need to be scaled up throughout the progression of implementation until it is clear whether or not the technology can, and will, be applied in a widespread manner.

Thus far, the majority of fiscal support for the research phase of cffDNA testing, which is occurring primarily in academic research centers, has been in the form of grants or endowments from government agencies, private foundations, and institutional funds. The biotechnology industry has subsequently been pursuing the development of scalable tests based upon research results using venture

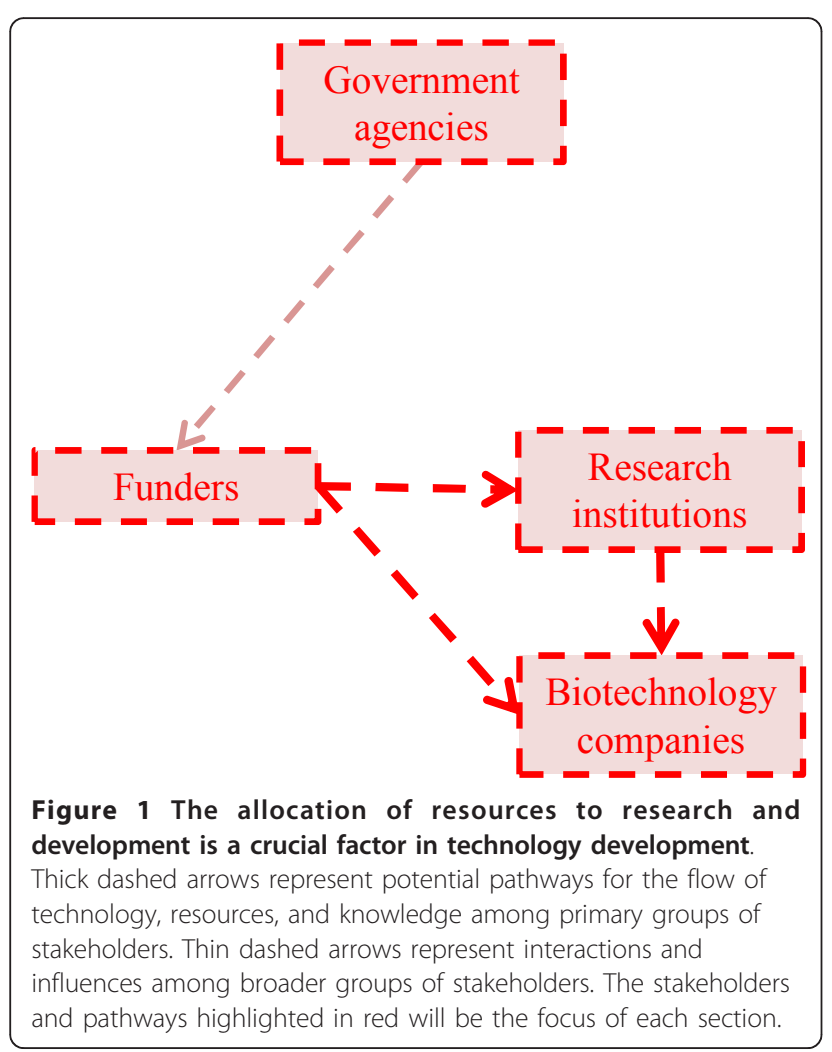

capital, grants, and other investments [28-30]. Until revenue can be secured, however, additional resources are required to apply the technology in its intended use. Biotechnology firms that are conducting studies to evaluate the clinical application of cffDNA testing must be capable of attracting sufficient financial support to underwrite these activities. As cffDNA testing for aneuploidy becomes clinically available, the source and size of capital investment will need to adjust to meet the changing priorities of its commercializers and users [31]. Private and state health insurance agencies have already become involved in dictating the implementation of this technology at the point of care, through decisions of whether to cover the first commercially available cffDNA tests for aneuploidy [32]. Given insurers' continued support for extant prenatal screening and diagnostic techniques, it is essential to understand the priorities of these funders in order to identify likely trajectories for the translation of this new technology. Statements made by our study's interviewees suggest that, where possible, insurance coverage should be decided on the basis of several inputs, including the wishes of insurance program enrollees to receive testing, medical standard of care, and comprehensive comparative analyses to existing technologies.

\section{Research and development}

Scientists at academic institutions have designed several methods to test cffDNA for aneuploidy, and the biotechnology industry is currently aiming to validate these methods through clinical trials (Figure 2) [16]. During our stakeholder interviews, several scientists claimed that reliable testing is already feasible in the presence of skilled personnel and unlimited resources, which is consistent with the growing body of literature [12-15]. However, in considering the scaling-up or expansion of such testing to broader populations and resource-limited settings, developers face the challenge of maintaining sufficient levels of reliability to compete with existing, highly reliable diagnostic tests. A similar technology, which attempted to use fetal cells circulating in maternal blood for prenatal diagnosis, showed some success on a small scale, but a large trial failed to demonstrate sufficiently robust results, resulting in the almost complete rejection of the technology $[33,34]$. Initial evidence for cffDNA testing for aneuploidy indicates that this technology may achieve more promising outcomes; however, ongoing validation and dissemination of study results will be an important facet of successful clinical implementation of this technology [12-15]. In both interviews and the literature, we have witnessed several physician calls for validation studies that are reproducible across populations of all risk levels and variable clinical and laboratory conditions, which were ultimately never achieved by fetal cell technologies [35]. 


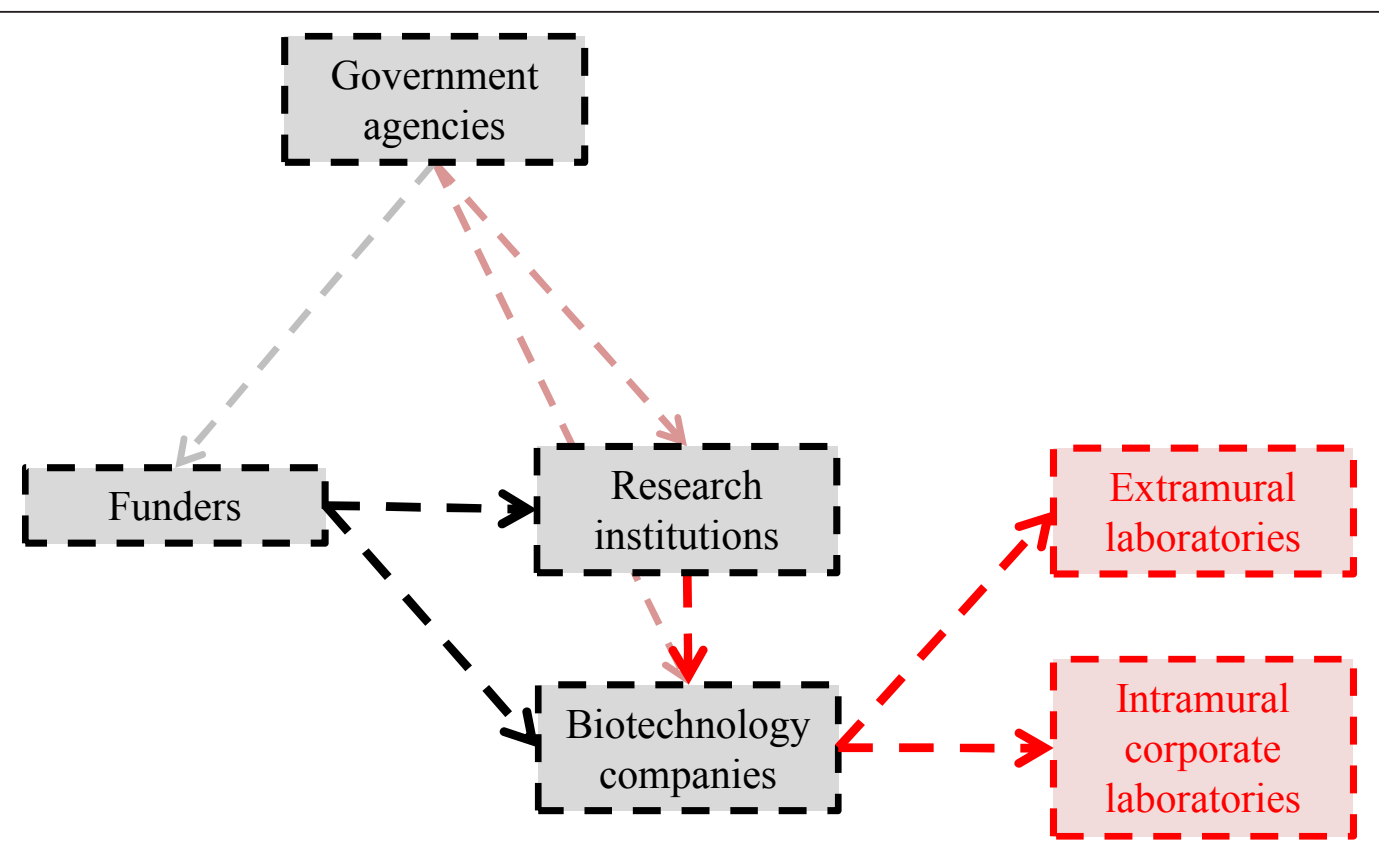

Figure 2 The structure and location of research and development activities has downstream effects on translation.

Many researchers in this field hold dual roles as faculty in academic laboratories and as executives, board members, or consultants for biotechnology companies tasked with commercializing cffDNA tests. Several of these individuals have been awarded patents for cffDNA testing strategies, and the licensing and information-sharing strategies of these patent holders have dictated which biotechnology companies are in a position to translate these methods into clinical applications. Thus far, these companies have utilized their in-house laboratories to conduct aneuploidy testing $[13,36]$. However, once a satisfactory large-scale commercial test has been developed, it is unclear whether companies will require that all samples be sent to their intramural laboratories for testing (and whether they have the infrastructure for such large-scale operations) or whether they will sublicense their methods such that independent clinical laboratories can perform the tests. In previous instances, companies with rights to patents for specific genes have stringently enforced monopolies through the threat of lawsuits and limited the provision of commercial testing to their internal laboratories [37].

If patent holders for cffDNA testing choose to restrict licensing, there may be a significant impact on availability of the technology, raising concerns of distributive justice, in addition to the potentially troubling implications for provider and patient independence in clinical decision-making [38]. Several studies suggest that

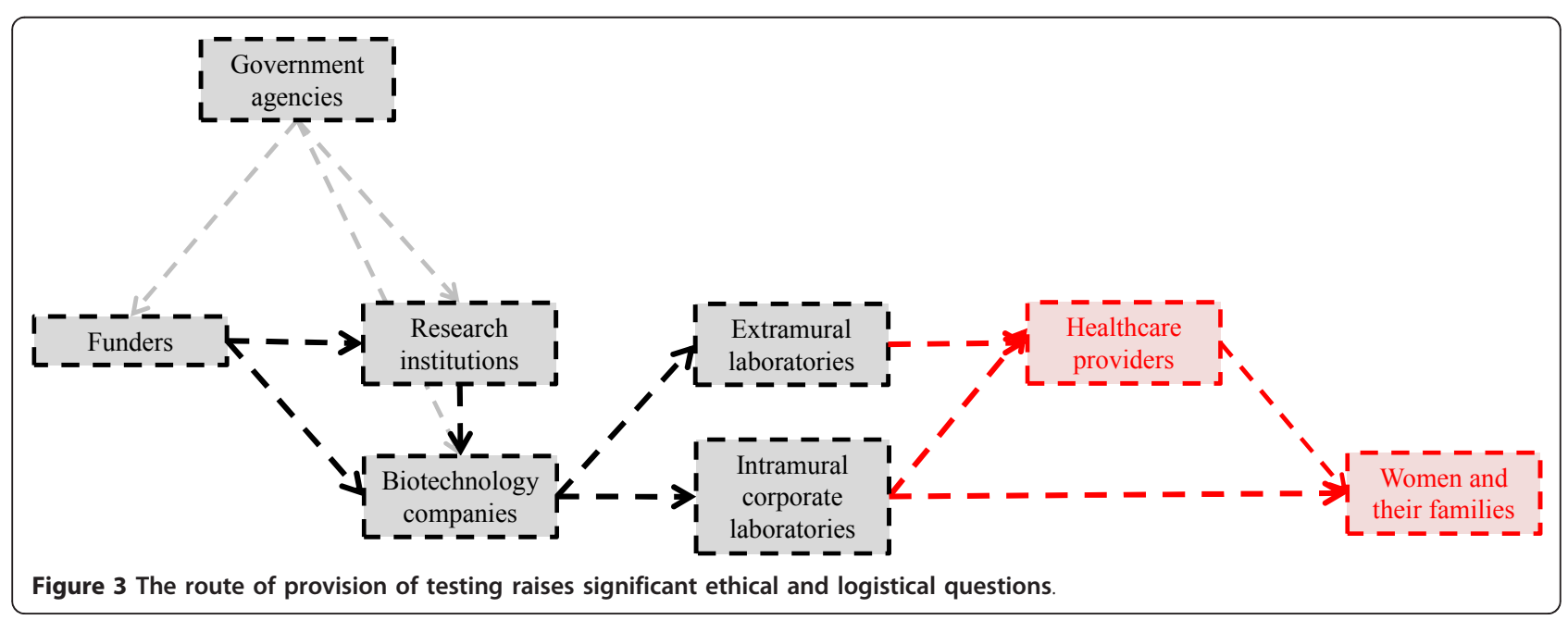




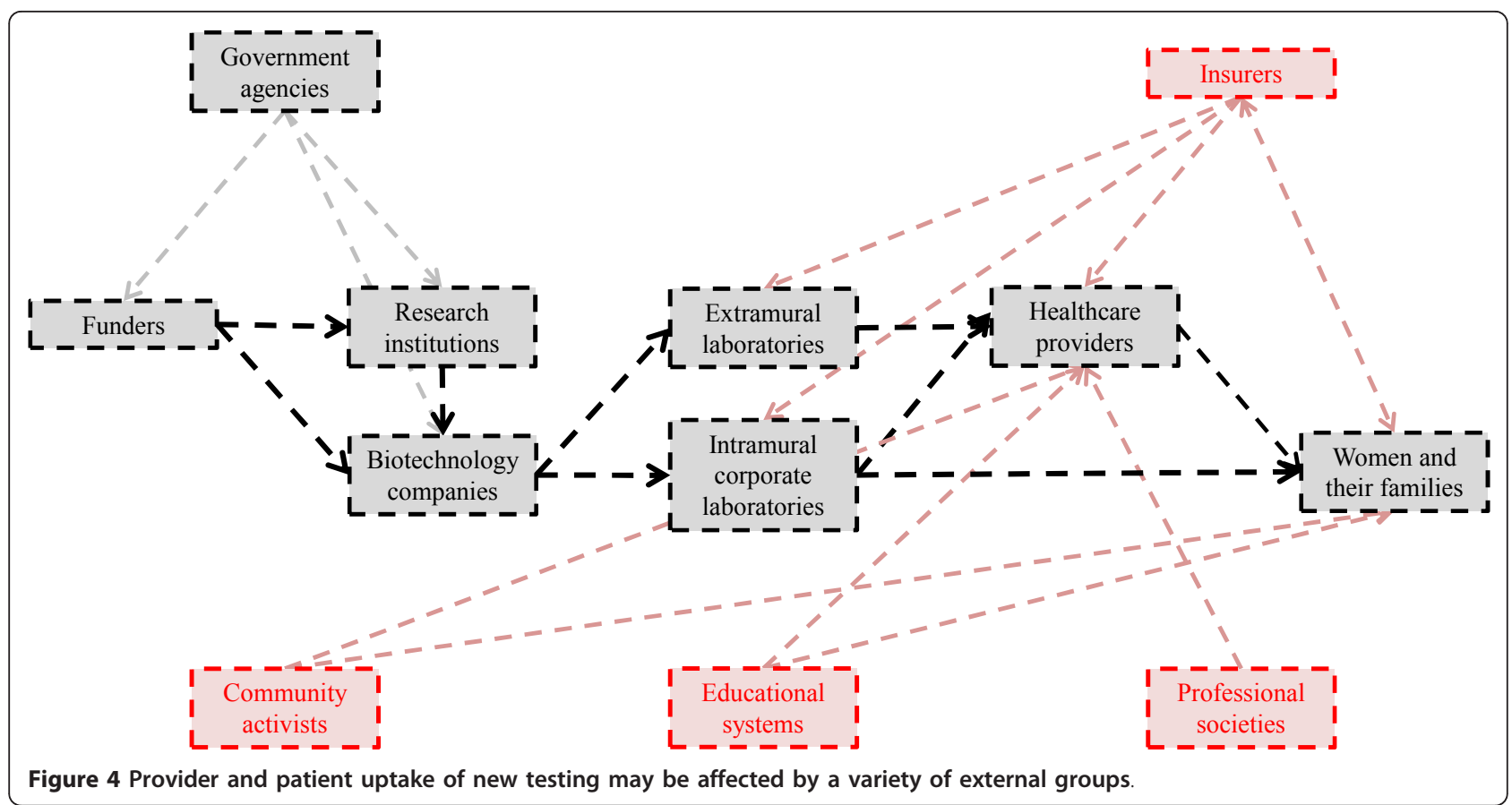

market exclusivity resulting from patents and restrictive licensing strategies for genetic tests negatively impacts development, cost, and access to testing $[39,40]$. The ongoing judicial case challenging patents covering the breast and ovarian cancer susceptibility genes BRCA1 and $B R C A 2$, held by the company Myriad Genetics, may thus have a significant effect on the course and implications of patenting for cffDNA testing if the validity of patents on genes or genetic diagnostic technologies is called into question [41]. Furthermore, because of the possibility of overlap among existing patent claims surrounding cffDNA testing, the enforcement of patents through infringement suits may have a drastic effect on the translational route of this testing. Despite the fact that legislation, such as the Bayh-Dole Act, is intended to promote translation from academic institutions to the






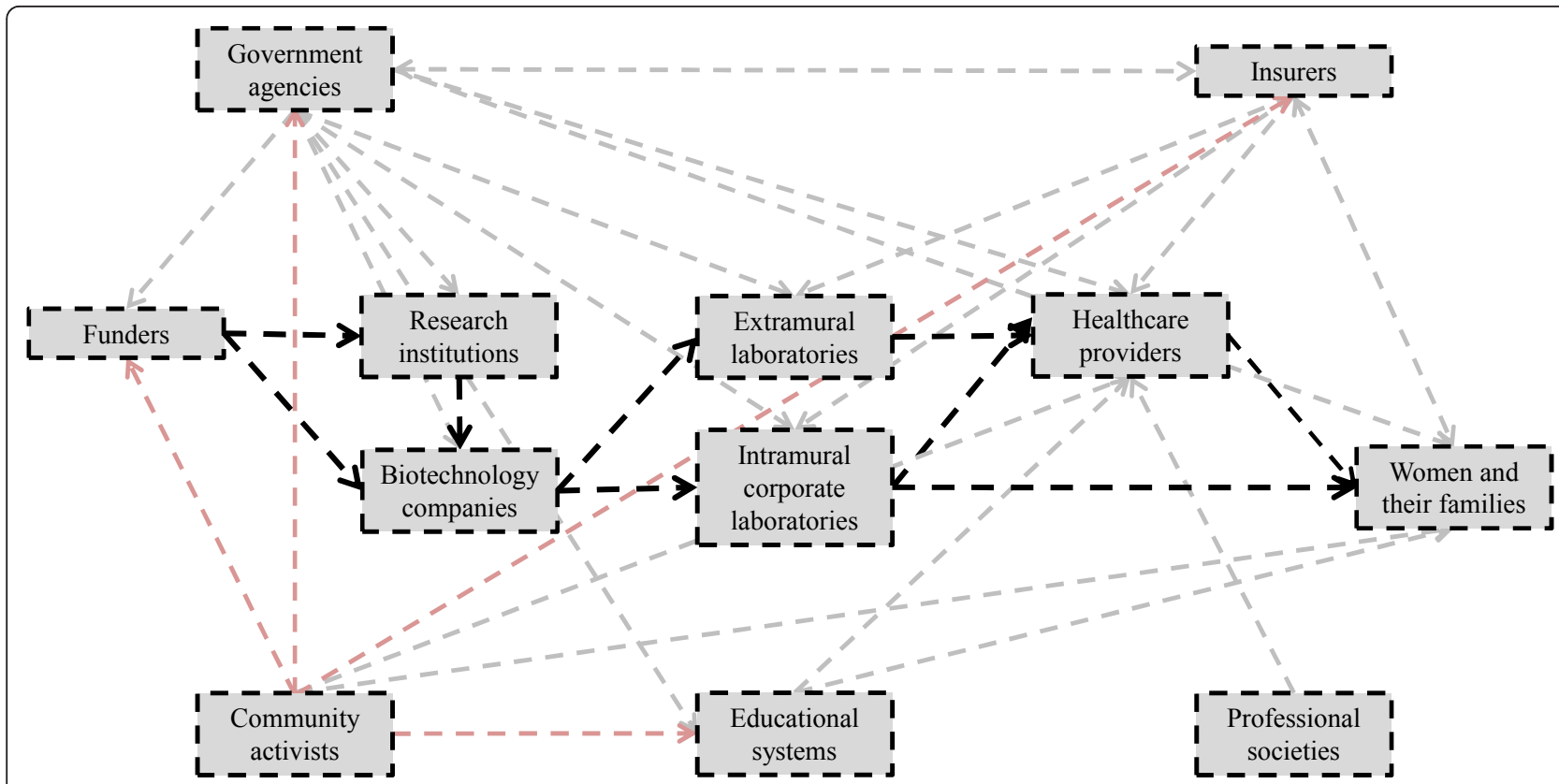

Figure 6 Activists can place pressure on key stakeholders, which may directly affect translation.

biotechnology industry in just this way, enforcement of patents on cffDNA testing may have the unintended consequence of raising barriers to dissemination [42]. While protectable intellectual property is an important and sometimes necessary incentive for product research and development, relevant commercializers and policymakers should bear in mind the potential broad repercussions of patenting and licensing practices on cffDNA testing for aneuploidy [24].

\section{Product dissemination}

If biotechnology companies intend to conduct cffDNA testing for aneuploidy through commercial laboratories, the possibility of direct-to-consumer (DTC) test provision, rather than provision through a healthcare professional, arises (Figure 3). DTC genetic testing has inspired intense debate as the medical community and the public try to strike a balance between empowering individuals to learn about their genetic makeup and protecting them from information with an unsound scientific basis or unclear health implications $[43,44]$. The current controversy over the appropriateness of placing genetic information directly in the hands of consumers becomes more pronounced when decisions to continue or terminate a pregnancy may result from inaccurate or misunderstood test results [45]. Responses to our pilot survey of obstetric healthcare providers demonstrate reservation about the potential availability of DTC cffDNA testing, and furthermore, respondents and interviewees alike indicated that they believe that genetic counseling should be utilized in order for pregnant women wishing to receive testing to understand this technology's indications, limitations, and implications [26]. A policy requiring comprehensive consent and counseling procedures before provision of genetic testing would additionally be in line with the positions of several relevant professional societies, including the American College of Medical Genetics, the National Society of Genetic Counselors, and the American Medical Association [46-48].

Existing cffDNA tests for trisomy 21 and RhD blood group type are currently available only via physician referral, whereas non-invasive prenatal sex testing can be ordered directly by a pregnant woman via the internet $[16,17]$. With the exception of commercial trisomy 21 tests, no data on the uptake of cffDNA tests have been made publicly available yet, so it is unclear how many tests are being performed. In a previous study of obstetric providers, a majority reported moderate to low levels of knowledge about availability of cffDNA testing, although most were simultaneously interested in offering this type of testing for aneuploidy [26].

Most predominant in dictating provider uptake of cffDNA testing may be the recommendations put forward by relevant professional societies, as surveyed healthcare providers demonstrated nearly unanimous reliance on such guidelines in future decision-making surrounding the adoption of cffDNA testing [26]. Historically, rapid and widespread uptake of prenatal alpha-fetoprotein screening for neural tube defects was almost exclusively the result of one statement issued by the legal committee of American Congress of Obstetricians and Gynecologists, despite its marked incompatibility with a previously issued statement from the organization [49]. 
Moreover, this uptake occurred at a time when clinicians were apprehensive about the limitations of such screening and were still calling for further studies and services coordination before screening was accessed by broad patient populations [49]. Fear of liability may ultimately have driven implementation of this technology. In the case of cffDNA testing for aneuploidy or other indications, professional societies should comprehensively consider the ethical, legal, social, political, and economic repercussions of testing before issuing unified messages for their constituents.

A number of other factors will affect whether physicians do ultimately offer these tests to their patients: whether a physician order is required for testing, the reliability and timing of the test, clinicians' perception of effectiveness and trust in the testing laboratories, insurance coverage, and perceived or expressed patient wishes. Furthermore, the current framework of prenatal screening and diagnostic options for genetic conditions such as aneuploidy will also affect whether providers adopt cffDNA testing; a reluctance to accept novel technologies or a vested interest in existing technologies may present barriers to widespread implementation. Assessing provider values and attitudes surrounding how this testing should be made commercially available will be an essential step in ensuring that the goals and characteristics of testing match the objectives of its stakeholders.

\section{Product uptake}

Like many medical technologies, the interface between end users and cffDNA testing for aneuploidy influences the trajectory of its implementation (Figure 4). Questions about how patients perceive and interpret benefits and risks in their choice to use (or not to use) this testing are critical. Potential benefits may include non-invasiveness, earlier timing, and increased reliability over existing screening tests. Personal reasons to decline cffDNA testing are more difficult to tease apart but may include objections to prenatal testing or selective termination of pregnancy, either for any genetic condition or specifically for a given aneuploidy; as with the refusal of other prenatal testing, these objections may stem from individual moral judgments or experiences, familial, provider, or social pressures, religious traditions, and broader cultural attitudes [50-53]. The diagnostic capability of cffDNA testing for aneuploidy will also inform how patients reflect on the benefits and costs of this technology relative to existing screening and diagnostic tests. Costs and accessibility of prenatal care or the availability of resources to raise a child with a given aneuploidy may additionally influence pregnant women at the time of decision-making.

In addition, access to information about a technology impacts uptake. In the past, DTC sex testing using
cffDNA has generated controversy when consumers, who felt that they had received insufficient information about the possibility of inaccurate results, brought a class-action suit against the company offering the test [54]. Negative publicity, and especially legal action, has the potential to modify and even reverse the course of implementation of cffDNA testing. Additionally, this case elucidates the fact that the non-invasive nature and thus modified benefit-risk calculation for cffDNA testing may undermine the integrity of the informed consent process, even when tests are provided solely through healthcare professionals [55]. Given that pregnant patients undergo a number of unrelated blood draws during early pregnancy, there is evidence to suggest that even trained professionals are not always thorough in obtaining informed consent when the physical risks of a test are so significantly reduced [56]. There is a concern that patients, if unaware that they are undergoing prenatal testing, will feel that their autonomy and decisionmaking has been compromised [57]. In order to avoid a loss of trust in novel prenatal testing methodologies, both healthcare providers - including obstetricians, genetic counselors, specialized nurses, and other allied health professionals - and potential patients need to be educated about the nature and availability of cffDNA testing. Stakeholders with whom we engaged additionally recommended genetic counseling as a necessary step in attaining the full engagement of patients in the decision-making process, which is consistent with our findings in the healthcare provider population [26].

Through coverage decisions, insurance agencies also have the ability to influence how and whether cffDNA testing for aneuploidy is accessed. One company currently offering cffDNA tests for trisomy 21 has set drastically differential prices ( $\$ 1,900$ as opposed to $\$ 235)$ for consumers based on whether they have insurance coverage [17]. Many women may not be able to afford the outof-pocket expenses or may choose to decline more expensive options when insurers already cover other tests. Insurance programs will likely assess the cost-benefit ratio of this technology in the context of the established framework of prenatal screening and diagnostic tests for aneuploidy. By exploring testing reliability, timing, and indications, insurers will determine whether implementation is appropriate as a reimbursable primary or secondary screening mechanism or as a diagnostic technique. If a decision is made to not cover cffDNA testing for aneuploidy, this testing may remain accessible only to a wealthy few or never realize commercial success at all. Regional mechanisms for offering testing to large subsets of the population, such as the California Prenatal Screening Program, must also be considered in determining the relevant stakeholders in the dissemination of this technology. If state law requires the offering and coverage 
of cffDNA testing for all pregnant women seeking prenatal care, as California law currently requires for integrated screening, uptake may be significantly increased. If cffDNA testing for aneuploidy is found to be a costeffective, desirable prenatal technology, federal and state reimbursement and dissemination strategies should strive for equity in access across all appropriate patient populations.

\section{Legal context}

Government agencies will play an important role in the implementation of cffDNA testing for aneuploidy at several translational stages (Figure 5). As a primary source of funding for research on prenatal testing and a potential buyer of this testing (through state insurance agencies), the government's control over financial resources has the potential to drive forward or inhibit development and use of this technology. Judicial decisions also have the potential to influence translational pathways through pertinent legal cases, such as those involving patenting and licensing, consumer interactions with companies, or communications between patients and healthcare providers by means of wrongful birth suits $[58,59]$. For example, a recent lawsuit in Oregon resulted in the awarding of several million dollars to parents claiming to have otherwise ended a pregnancy had they received an accurate prenatal diagnosis of trisomy 21; with new technologies like cffDNA testing being made available, pressures will mount for physicians to avoid liability by offering any and all tests to ensure that affected pregnancies are detected [60]. Other stakeholders will have important influences over the initiation and outcomes of such legal cases; for example, in the aforementioned case involving Myriad Genetics, physicians, patients, professional societies, and community activists filed a suit that may influence the legality of gene patenting. In the case of cffDNA testing for aneuploidy, we have already started to witness a surge of legal action pursued by various patent and license holders that may critically influence the characteristics of technological implementation [61].

Currently, government regulation of many genetic tests does not extend beyond certification of clinical laboratories under the Clinical Laboratory Improvement Amendments, administered by the Centers for Medicare and Medicaid Services. However, the Food and Drug Administration (FDA) has the authority to assign classifications (I, II, or III) to all medical devices and to apply increasingly stringent standards for their regulation. Historically, the implicit endorsement of a technology under FDA regulation has led to drastic consequences on uptake; for example, it was only following FDA approval of alpha-fetoprotein screening of maternal serum that American Congress of Obstetricians and Gynecologists issued its legal position that essentially assigned this novel technology as the universal standard of care [49]. A public determination has yet to be made regarding the classification of cffDNA testing for aneuploidy. Given public hearings and the sending of cease-and-desist letters to a number of companies offering genetic tests, including one company offering cffDNA testing for $\mathrm{RhD}$ blood type, the FDA may intend to regulate this technology as a medical device in the future [62,63]. Commercially available medical devices require pre-market notification or pre-market approval from the FDA and in response, at least one firm developing cffDNA technology has indicated that it intends to file for pre-market approval of its trisomy 21 test [64]. Given the current uncertainties of the regulatory environment, these government agencies have the ability to dictate the features and course of implementation of aneuploidy testing using cffDNA.

\section{Social context}

As with the introduction of other prenatal technologies, campaigns that endorse or oppose the use of cffDNA testing for aneuploidy are likely to originate among activist communities, such as the disability rights community (Figure 6) [65,66]. In particular, advocacy groups for specific genetic conditions, such as trisomy 21 , raise significant concerns about the underlying suggestion of prenatal testing that disability is something to be avoided and suggest that, while prenatal testing in and of itself may be acceptable, discussions surrounding prenatal options must be comprehensive, sensitive, and without undue pressures on prospective parents. Another group with considerable interest in this technology includes individuals who oppose abortion and strongly disagree with any prenatal technology that could lead to increased rates of pregnancy termination. Equally relevant groups are feminist communities or other groups in civil society that campaign for reproductive liberties, who may argue that pregnant women have an inherent right to obtain fetal genetic information via prenatal testing [67].

The influences of activism in multiple directions may manifest in state legislation over the scope of lawful prenatal testing and pregnancy termination; current legislative trends in the US include increasing restrictions on abortion [68]. In the past, some of these communities have had considerable impact on the course of research and translation of genetic technologies, through lobbying efforts, provision of research funding, and educational activities for the public and healthcare providers [67,70]. Moreover, litigation brought by private citizens, such as the aforementioned cases involving DTC cffDNA testing for fetal sex or the validity of patents on $B R C A$ genetic testing, may allow the broader public to redirect future commercialization activities and uptake of these technologies $[40,41,54]$. 
As with all realms, a balance must be struck between allowing interest groups, including those whose voices are often neglected, to be heard and preventing any one constituency from wielding power to introduce genetic technologies that are ineffective or undesirable at a societal level.

At the individual level, these social and political activities may have sufficient influence to alter opinions, and thus uptake, of this technology. To the individual, the debate over whether prenatal testing or termination of pregnancy for aneuploidy is morally acceptable and the appropriate use of such information is rarely as dichotomized as it may appear on the political stage. The application of personal values to novel reproductive choices is not clear cut; pregnant women draw from intersecting and opposing messages from their healthcare providers, family, religion, culture, and society in facing such decisions [50-53]. Furthermore, families may seek prenatal test information for many reasons other than deciding whether to terminate a pregnancy; it has been an unfortunate consequence that prenatal testing technologies are often only thought of merely as precursors to selective abortions. In the related history of the implementation of maternal serum screening for aneuploidy, pregnant women often left discussions with their physicians concerned that a positive screen or test result was assumed to be cause for termination of the pregnancy. Patients ended up being unclear about the purposes or implications of screening given either their doctors' uncertainty about testing features or the lack of comprehensive, clear, and culturally sensitive communication and counseling before screening, particularly in the context of their already-complex decision-making processes surrounding uptake of this screening [52,71]. Given the parallels between cffDNA testing and this previous technology, we suggest that mechanisms be put in place to encourage careful and complete discussions among providers and prospective parents.

Ascertaining the attitudes of specific activist groups and broader sets of stakeholders, including the general public, and, to the greatest extent possible, aligning their objectives within proposed translational pathways is critical to the successful implementation of this technology. In addition, aggregate social attitudes towards cffDNA testing may influence uptake; if this testing is perceived as presenting new options to prospective parents, it is also possible that parents will be perceived as irresponsible for not availing themselves of these options [72,73]. Such attitudinal shifts may create a coercive environment for decisionmaking.

\section{Summary}

Successful implementation of cffDNA testing for aneuploidy should involve the consideration of potential translational pathways and their consequences from the perspective of diverse sets of stakeholders. For example, it is critical to understand how these pathways will be influenced by the values of pregnant women, their families, and healthcare providers and mediated by the agendas of judicial and regulatory bodies, payers, professional societies, educational systems, and representatives from civil society. Throughout the translational course, researchers and developers should solicit the early and continued participation of these stakeholders in order to ensure that their visions for the ultimate use of this testing are compatible and avoid inefficient, inappropriate, or otherwise unsuccessful attempts at translation. We hope that our initial sketches of stakeholder interactions will provide a framework in which the pathways to implementation of this technology can be explored in further detail via consultation and collaboration with an array of stakeholders representing the six classes that we have described. As part of a more comprehensive study on stakeholder attitudes towards cffDNA technology, we plan to develop an interactive forum whereby diverse stakeholders, including those from traditionally underrepresented categories, can express their values and opinions and respond to the priorities of others; we urge others to develop similar methodologies for engaging stakeholders and presenting findings to those in positions to enact policies and practices that have achieved consensus among stakeholders.

\section{Moving forward with genomic medicine}

Using cffDNA testing for aneuploidy as an example of an emerging genomic technology, we have illustrated how complex and uncertain translational pathways may be. Analyzing the priorities and dynamics among stakeholders may help to identify factors that may impact implementation and achieve a true picture of technological translation. Our assessment represents a departure from conventional technology assessment methods, which consider features inherent to the technology itself. Such assessments generally limit the inclusion of stakeholder values and lack critical historical perspectives. The situation of cffDNA testing among both genetic and reproductive technologies creates special demands on a translational analysis of this sort, requiring attention to a particularly wide scope of stakeholders and a rich history of technological, social, and political successes and failures. While the features and contextual details of other genomic technologies vary widely and must be considered on an individual basis, we argue that the successful development and provision of any new technology must be predicated on the flow of information and ideals surrounding its real and desired features among all of its stakeholders. Utilizing this framework to trace and elaborate upon translational pathways will, we believe, lead to the translation of cffDNA testing for aneuploidy in the most 
ethically sound manner. We hope that it may also provide a starting place for the consideration of other novel technologies - with their own unique frameworks of translational pathways - in order to achieve the goal of genomic translation in the years to come.

\section{Abbreviations}

cffDNA: cell-free fetal DNA; DTC: direct-to-consumer; FDA: Food and Drug Administration.

\section{Acknowledgements}

All authors are supported by NIH grant P50 HG003389 (Stanford Center for Integrating Ethics and Genetic Research). MKC is additionally supported by NIH grant 1 U54 RR024374-01A1 (Stanford Center for Clinical and Translational Education and Research). The funding body had no role in the design, collection, analysis, and interpretation of data; in the writing of the manuscript; and in the decision to submit the manuscript for publication.

\section{Author details}

'Stanford Center for Biomedical Ethics, Stanford University, 1215 Welch Road Modular A, Stanford, California, 94301, USA. ²Department of Pediatrics, Division of Genetics, Stanford University, 1215 Welch Road Modular A, Stanford, California, 94301, USA.

\section{Authors' contributions}

All authors conceived of the study and participated in its design and coordination. LCS conducted the interviews and drafted a preliminary version of the manuscript. All authors provided substantial suggestions for the manuscript and have read and approved the final manuscript for publication.

\section{Competing interests}

The authors declare that they have no competing interests.

Received: 6 January 2012 Revised: 23 May 2012

Accepted: 21 June 2012 Published: 21 June 2012

\section{References}

1. Green ED, Guyer MS: Charting a course for genomic medicine from base pairs to bedside. Nature 2011, 470:204-213.

2. Brugha R, Varvasovszky Z: Stakeholder analysis: a review. Health Policy Plan 2000, 15:239-246.

3. Burgess MM: Public consultation in ethics: an experiment in representative ethics. J Bioeth Inq 2004, 1:4-13.

4. Holtzman NA: The diffusion of new genetic tests for predicting disease. Faseb J 1992, 6:2806-2812.

5. Khoury MJ, Gwinn M, Yoon PW, Dowling N, Moore CA, Bradley L: The continuum of translation research in genomic medicine: how can we accelerate the appropriate integration of human genome discoveries into health care and disease prevention?. Genet Med 2007, 9:665-674.

6. Roth JA, Garrison LP Jr, Burke W, Ramsey SD, Carlson R, Veenstra DL: Stakeholder perspectives on a risk-benefit framework for genetic testing. Public Health Genomics 2011, 14:59-67.

7. Veenstra DL, Roth JA, Garrison LP Jr, Ramsey SD, Burke W: A formal riskbenefit framework for genomic tests: facilitating the appropriate translation of genomics into clinical practice. Genet Med 2010, 12:686-693.

8. Wilfond BS, Nolan K: National policy development for the clinical application of genetic diagnostic technologies. Lessons from cystic fibrosis. JAMA 1993, 270:2948-2954

9. Gaskell G, Bauer MW, Durant J, Allum NC: Worlds apart? The reception of genetically modified foods in Europe and the U.S. Science 1999, 285:384-387.

10. Thompson L: Human gene therapy: harsh lessons, high hopes. FDA Consumer 2000, 34:19-24

11. Wilson JM: Medicine. A history lesson for stem cells. Science 2009, 324:727-728.

12. Palomaki GE, Kloza EM, Lambert-Messerlian GM, Haddow JE, Neveux LM, Ehrich M, van den Boom D, Bombard AT, Deciu C, Grody WW, Nelson SF,
Canick JA: DNA sequencing of maternal plasma to detect Down syndrome: An international clinical validation study. Genet Med 2011, 13:913-920

13. Sehnert AJ, Rhees B, Comstock D, de Feo E, Heilek G, Burke J, Rava RP: Optimal detection of fetal chromosomal abnormalities by massively parallel DNA sequencing of cell-free fetal DNA from maternal blood. Clin Chem 2011, 57:1042-1049.

14. Ehrich M, Deciu C, Zwiefelhofer T, Tynan JA, Cagasan L, Tim R, Lu V, McCullough R, McCarthy E, Nygren AO, Dean J, Tang L, Hutchison D, Lu T, Wang $H$, Angkachatchai V, Oeth P, Cantor CR, Bombard A, van den Boom D: Noninvasive detection of fetal trisomy 21 by sequencing of DNA in maternal blood: a study in a clinical setting. Am J Obstet Gynecol 2011, 204:1-11.

15. Chiu RW, Akolekar R, Zheng YW, Leung TY, Sun H, Chan KC, Lun FM, Go AT, Lau ET, To WW, Leung WC, Tang RY, Au-Yeung SK, Lam H, Kung YY, Zhang $X$, van Vugt JM, Minekawa R, Tang MH, Wang J, Oudejans CB, Lau TK, Nicolaides KH, Lo YM: Non-invasive prenatal assessment of trisomy 21 by multiplexed maternal plasma DNA sequencing: large scale validity study. BMJ 2011, 342:7401.

16. Sayres LC, Cho MK: Cell-free fetal nucleic acid testing: a review of the technology and its applications. Obstet Gynecol Surv 2011, 66:431-442.

17. Heger M: Sequenom launches MaterniT21 Down syndrome test as LDT, publishes clinical validation study. Clinical Sequencing News 2011 [http:// www.genomeweb.com/sequencing/sequenom-launches-maternit21-downsyndrome-test-ldt-publishes-clinical-validatio]

18. Verinata Health: Technology.[http://www.verinata.com/providers/providerstechnology/].

19. Ariosa Diagnostics: Prenatal testing options.[http://www.ariosadx.com/ review-clinical-data/prenatal-testing-options/].

20. Natera : Non-invasive prenatal testing.[http://www.natera.com/noninvasive-prenatal-testing.html].

21. Greely HT: Get ready for the flood of fetal gene screening. Nature 2011, 469:289-291.

22. Roelofsen A, Broerse JEW, de Cock Buning T, Bunders JFG: Exploring the future of ecological genomcs: Integrating CTA with vision assessment. Technological Forecasting and Social Change 2008, 75:334-355.

23. Schot J, Rip A: The past and future of constructive technology assessment. Technological Forecasting and Social Change 1996, 54:251-268.

24. Williams-Jones B, Graham JE: Actor-network theory: a tool to support ethical analysis of commercial genetic testing. New Genet Soc 2003, 22:271-296.

25. Ginsburg GS: Genomic Medicine: 'grand challenges' in the translation of genomics to human health. Eur J Hum Genet 2008, 16:873-874.

26. Sayres LC, Allyse M, Norton ME, Cho MK: Cell-free fetal DNA testing: a pilot study of obstetric healthcare provider attitudes toward clinical implementation. Prenat Diagn 2011, 31:1070-1076.

27. Brown N, Michael M: A sociology of expectations: Retrospecting prospects and prospecting retrospects. Technol Anal Strateg 2003, 15:3-18.

28. Sequenom files $\$ 150 \mathrm{M}$ shelf registration with SEC.. GenomeWeb Daily News 2011 [http://www.genomeweb.com/mdx/sequenom-files-150m-shelfregistration-sec].

29. Prenatal $d x$ test firm Verinata raising $\$ 48.5 M$. . GenomeWeb Daily News 2011 [http://www.genomeweb.com/dxpgx/prenatal-dx-test-firm-verinataraising- $485 \mathrm{~m}]$.

30. Business Wire: Gene Security Network completes funding to expand into new DNA testing markets.[http://www.businesswire.com/news/home/ 20101101005725/en/Gene-Security-Network-Completes-Funding-ExpandDNA].

31. Chachkin CJ: What potent blood: Non-invasive prenatal genetic diagnosis and the transformation of modern prenatal care. Am J Law Med 2007, 33:9-53.

32. Heger M: Sequenom receives first samples for MaterniT21, plans expansion and sample-prep automation for 2012. Clinical Sequencing News 2011 [http://www.genomeweb.com/sequencing/sequenom-receivesfirst-samples-maternit21-plans-expansion-and-sample-prep-autom].

33. Bianchi DW, Simpson JL, Jackson LG, Elias S, Holzgreve W, Evans MI, Dukes KA, Sullivan LM, Klinger KW, Bischoff FZ, Hahn S, Johnson KL, Lewis D, Wapner RJ, de la Cruz F: Fetal gender and aneuploidy detection using fetal cells in maternal blood: analysis of NIFTY I data. National Institute of Child Health and Development Fetal Cell Isolation Study. Prenat Diagn 2002, 22:609-615. 
34. Bianchi DW, Hanson J: Sharpening the tools: a summary of a National Institutes of Health workshop on new technologies for detection of fetal cells in maternal blood for early prenatal diagnosis. J Matern Fetal Neona 2006, 19:199-207.

35. Simpson JL: Is cell-free fetal DNA from maternal blood finally ready for prime time?. Obstet Gynecol 2012, 119:883-885.

36. Ehrich M, Deciu C, Zwiefelhofer T, Tynan JA, Cagasan L, Tim R, Lu V, McCullough R, McCarthy E, Nygren AO, Dean J, Tang L, Hutchison D, Lu T, Wang $\mathrm{H}$, Angkachatchai $\mathrm{V}$, Oeth $\mathrm{P}$, Cantor $\mathrm{CR}$, Bombard $\mathrm{A}$, van den Boom D: Noninvasive detection of fetal trisomy 21 by sequencing of DNA in maternal blood: a study in a clinical setting. Am J Obstet Gynecol 2011, 204:201-211.

37. Merz JF, Cho MK: What are gene patents and why are people worried about them?. Community Genet 2005, 8:203-208.

38. Merz JF: Disease gene patents: overcoming unethical constraints on clinical laboratory medicine. Clin Chem 1999, 45:324-330.

39. Cho MK, Illangasekare S, Weaver MA, Leonard DG, Merz JF: Effects of patents and licenses on the provision of clinical genetic testing services. J Mol Diagn 2003, 5:3-8.

40. Angrist M, Carbone J, Chandrasekharan S, Colaianni A, Conover C, CookDeegan R, DeRienzo C, Evans JP, Fiffer M, Gold ER, Heaney C, James T, Pitlick E, Powell A, Skeehan K: Patently complicated: Case studies on the impact of patenting and licensing on clinical access to genetic testing in the United States. Genet Med 2010, 12:S1-S211.

41. Marshall E: U.S. Appeals Court backs gene patents in Myriad case. Science Insider 2011 [http://news.sciencemag.org/scienceinsider/2011/07/us-appealscourt-backs-gene-patents.html].

42. United States Patent and Trademark Office: Bayh-Dole Act. 35 USC 201-212.

43. Evans JP, Green RC: Direct to consumer genetic testing: Avoiding a culture war. Genet Med 2009, 11:568-569.

44. GAO: Direct-to-consumer genetic tests: Misleading test results are further complicated by deceptive marketing and other questionable practices.[http://www.gao.gov/products/GAO-10-847T].

45. Bianchi DW: At-home fetal DNA gender testing: caveat emptor. Obstet Gynecol 2006, 107:216-218.

46. American College of Medical Genetics: Statement on direct-to-consumer genetic testing: genetics professionals should be part of genetic testing process, says American College of Medical Genetics.[http://www.acmg. net/StaticContent/StaticPages/DTC_Statement.pdf].

47. National Society of Genetic Counselors: Direct to consumer genetic testing.[http://www.nsgc.org/Media/PositionStatements/tabid/330/Default. aspx\#DTC].

48. Maves MD, on behalf of American Medical Association: Molecular and Clinical Genetics Panel of the Medical Devices Advisory Committee; Notice of Meeting. Docket FDA-2011-N-0066 [http://www.ama-assn.org/ resources/doc/washington/consumer-genetic-testing-letter.pdf].

49. Annas GJ: Is a genetic screening test ready when the lawyers say it is?. Hastings Cent Rep 1985, 15:16-18.

50. Lippman A: Prenatal genetic testing and screening: constructing needs and reinforcing inequities. Am J Law Med 1991, 17:15-50.

51. Markens S, Browner CH, Press N: 'Because of the risks': how US pregnant women account for refusing prenatal screening. Soc Sci Med 1999, 49:359-369.

52. Press $\mathrm{N}$, Browner $\mathrm{CH}$ : Why women say yes to prenatal diagnosis. Soc Sci Med 1997, 45:979-989.

53. Rapp R: Refusing prenatal diagnosis: the meanings of bioscience in a multicultural world. Sci Technol Human Values 1998, 23:45-70.

54. Zand S: Parents Sue Over Pregnancy Test Said to Tell Baby's Sex. ABC News 2006 [http://abcnews.go.com/Health/story?id = 1668125\&page $=1$ ].

55. Smith RP, Lombaard H, Soothill PW: The obstetrician's view: ethical and societal implications of non-invasive prenatal diagnosis. Prenat Diagn 2006, 26:631-634.

56. van den Heuvel A, Chitty L, Dormandy E, Newson A, Deans Z, Attwood S, Haynes S, Marteau TM: Will the introduction of non-invasive prenatal diagnostic testing erode informed choices? An experimental study of health care professionals. Patient Educ Couns 2010, 78:24-28.

57. Deans Z, Newson AJ: Should non-invasiveness change informed consent procedures for prenatal diagnosis?. Health Care Anal 2011, 19:122-132.

58. Klein RD, Mahoney MJ: Medical legal issues in prenatal diagnosis. Clin Perinatol 2007, 34:287-297.
59. Press N, Browner $\mathrm{CH}$ : Risk, autonomy, and responsibility: informed consent for prenatal testing. Hastings Cent Rep 1995, 25:S9-12.

60. Carollo K: Parents get $\$ 2.9 \mathrm{M}$ in Down syndrome girl 'wrongful birth' suit. ABC News 2012 [http://abcnews.go.com/blogs/health/2012/03/10/parentsget-2-9m-in-down-syndrome-girl-wrongful-birth-suit/].

61. Verinata Health sues Sequenom over prenatal diagnostic patent rights. Clinical Sequencing News 2012 [http://www.genomeweb.com/sequencing/ verinata-health-sues-sequenom-over-prenatal-diagnostic-patent-rights].

62. Pollack A: F.D.A. Faults Companies on Unapproved Genetic Tests. The New York Times 2010 [http://www.nytimes.com/2010/06/12/health/ 12 genome.html].

63. Sequenom preparing response to FDA on warning letter.. GenomeWeb Daily News 2010 [http://www.genomeweb.com/dxpgx/sequenompreparing-response-fda-warning-letter].

64. Heger M: Sequenom in discussions with FDA on premarket application for sequencing-based trisomy 21 test. Clinical Sequencing News 2011 [http://www.genomeweb.com/sequencing/sequenom-discussions-fdapremarket-application-sequencing-based-trisomy-21-test].

65. Parens $E$, Asch $A$ : Disability rights critique of prenatal genetic testing: reflections and recommendations. Ment Retard Dev Disabil Res Rev 2003, 9:40-47.

66. Shakespeare T: Choices and rights: eugenics, genetics and disability equality. Disabil Soc 1998, 13:665-681.

67. Robertson JA: Genetic selection of offspring characteristics. Boston Univ Law Rev 1996, 76:421-482.

68. Gee A: Anti-abortion laws gain more ground in the USA. Lancet 2011, 377:1992-1993.

69. Cody JD: Creating partnerships and improving health care: the role of genetic advocacy groups. Genet Med 2006, 8:797-799.

70. Merz JF, Magnus D, Cho MK, Caplan AL: Protecting subjects' interests in genetics research. Am J Hum Genet 2002, 70:965-971.

71. Faden RR, Chwalow AJ, Orel-Crosby E, Holtzman NA, Chase GA, Leonard CO: What participants understand about a maternal serum alpha-fetoprotein screening program. Am J Public Health 1985, 75:1381-1384.

72. Rothman BK: The Tentative Pregnancy: Prenatal Diagnosis and the Future of Motherhood Viking; 1986.

73. Faden R: Reproductive genetic testing and the ethics of parenting. Fetal Diagn Ther 1993, 8:142-147.

doi:10.1186/gm348

Cite this article as: Sayres et al:: Integrating stakeholder perspectives into the translation of cell-free fetal DNA testing for aneuploidy. Genome Medicine 2012 4:49.

\section{Submit your next manuscript to BioMed Central and take full advantage of:}

- Convenient online submission

- Thorough peer review

- No space constraints or color figure charges

- Immediate publication on acceptance

- Inclusion in PubMed, CAS, Scopus and Google Scholar

- Research which is freely available for redistribution

Submit your manuscript at www.biomedcentral.com/submit
C Biomed Central 